\title{
Pelagic underyearling communities in a canyon-shaped reservoir in late summer
}

\author{
Tomáš JƯZA ${ }^{1,2) *}$, Mojmír VAŠEK ${ }^{1)}$, Jan KUBEČKA ${ }^{1,2)}$, Jaromír SEĎA ${ }^{1)}$, Josef MATĚNA ${ }^{1,2)}$, Marie PRCHALOVÁ ${ }^{1)}$, \\ Jiř́ PETERKA ${ }^{1)}$, Milan ŘÍHA ${ }^{1,2)}$, Oldřich JAROLÍM ${ }^{1,2)}$, Michal TUŠER ${ }^{1,2)}$, Michal KRATOCHVÍL ${ }^{1,2)}$, \\ Martin ČECH ${ }^{1)}$, Vladislav DRAŠTÍK ${ }^{1)}$, Jaroslava FROUZOVÁ ${ }^{1)}$, Eva HOHAUSOVÁ ${ }^{1)}$ and Jiř́ ŽALOUDÍK ${ }^{1)}$ \\ ${ }^{1)}$ Biology Centre of the Academy of Sciences of the Czech Republic, Institute of Hydrobiology, Na Sádkách 7, 37005 České \\ Budějovice, Czech Republic \\ ${ }^{2)}$ Faculty of Science, University of South Bohemia, Branišovská 31, 37005 České Budějovice, Czech Republic \\ *e-mail corresponding author: e-mail: tomas.juza@seznam.cz
}

\begin{abstract}
The community of pelagic fish fry present during late summer was studied in the canyon-shaped and eutrophic Rimov Reservoir, Czech Republic, using nighttime trawling over seven years. Cyprinid fish dominated in the open water area throughout the period investigated. The highest mean density of fry in the surface water layer was observed in 1999 (15 ind $\left.100 \mathrm{~m}^{-3}\right)$, the lowest in 2000 $\left(0.1\right.$ ind $\left.100 \mathrm{~m}^{-3}\right)$. A pronounced spatial gradient in the distribution of fry was observed in the reservoir in all years, with the highest densities in the upstream area and the lowest densities near the dam. Occurrence of cyprinids was highest in the upper area, while percid fry were distributed more regularly throughout the horizontal gradient from the lower to upper areas of the reservoir. Vertically, the cyprinids were confined almost entirely to the near-surface water layer, whereas the percids dominated in the deeper strata (3-6 $m$ depth) in all years investigated. Catches in the deepest layer sampled (between 6 and 9 meters) were only sporadic. No significant correlations between fry density and biotic or abiotic factors were observed during the seven years investigated, neither for the dominant fish species pooled together nor for separate fish species. The observed spatial gradients of fry density, both horizontal and vertical, are similar to spatial gradients of older fish. The longitudinal gradient of fry density seems to be a result of reservoir morphology (a gradient of the relative volume of the littoral) rather than other limiting biotic or abiotic factors.
\end{abstract}

Key words: fry community, spatial distribution, fry trawling, environmental factors, reservoir morphology

\section{INTRODUCTION}

Deep valley reservoirs are characterized by an elongated morphometry (thus, they are frequently termed canyon-shaped reservoirs) and pronounced longitudinal physical and chemical gradients imposed by the river inflow (Lind et al. 1993). These longitudinal enviromental gradients influence the horizontal distributions of phytoplankton (Fernández-Rosado et al. 1994; Hejzlar \& Vyhnálek 1998), zooplankton (Sed’a \& Devetter 2000; Fernández-Rosado \& Lucena 2001) and, consequently, fish (Oliveira et al. 2004; Vašek et al. 2004; Vašek et al. 2006; Čech et al. 2007a; Čech et al. 2007b; Prchalová et al. 2009) within the pelagic zone of deep valley reservoirs. Beside the horizontal spatial heterogeneity, the pelagic environment also varies vertically in deep reservoirs, especially in those which have relatively long retention times enabling the development of thermal stratification. Consequently, depth is another important spatial scale at which the abundance and structure of fish communities can vary with respect to both abiotic and biotic factors (Bohl 1980; Fernando \& Holčík 1991; George \& Winfield 2000; Masson et al. 2001; Vašek et al. 2006). Deep valley reservoirs, with their within-system spatial heterogeneity, thus represent unique opportunities for assessing the effects of variable environmental conditions on the structure and functioning of fish communities.
Fry samples from littoral areas of lakes, rivers and reservoirs are commonly collected using seining techniques (Kubečka \& Švátora 1993; Jurajda et al. 1997; Macháček \& Matěna 1997) or point abundance electrofishing (Copp \& Jurajda 1993; Okun \& Mehner 2005; Okun et al. 2005). Pelagic fry have been intensively studied in their ichthyoplankton stages using ichthyoplankton nets or smaller samplers (Matěna 1995; Frankiewicz et al. 1996; Wanzenböck et al. 1997; Rudstam et al. 2002; Čech et al. 2005; Čech et al. 2007b) but quantitative night trawling for sampling late summer juveniles (Jůza \& Kubečka 2007) has demonstrated considerable efficacy in sampling the early life history of fry, when most processes of their first season (spawning success, growth, mortality) have already taken place. To date, there is a paucity of data on patterns of open water fry communities in lakes and reservoirs during late summer (Mills \& Forney 1983; Gliwicz \& Jächner 1992; Vašek et al. 2006). However, knowledge of species composition, distribution and densities of fry communities during this part of the year is valuable for assessment of trophic web interactions and for the correct management of fish populations.

For this paper, spatial and temporal variations of late summer pelagic communities were examined in an eutrophic reservoir system, the Rímov Reservoir, Czech Republic, over a period of 7 years.

The main aims of the study were: 


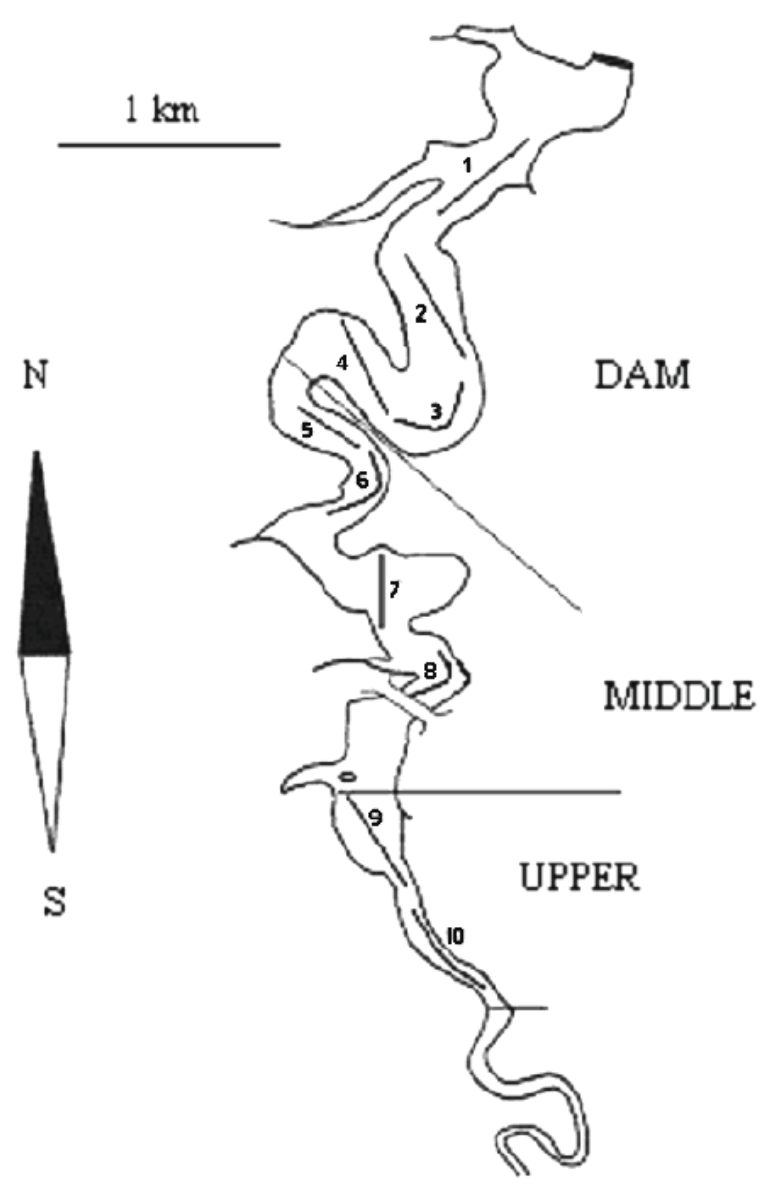

Fig. 1. Map of the Rímov Reservoir and locations of trawler hauls in three areas along the longitudinal reservoir profile.

1) to determine whether there exist interannual differences in pelagic fry species composition and fry densities and which biophysical factors could influence fry density in late summer. During early spring, shortly after hatching, percids dominated the open water area of the Rímov Reservoir (Matěna 1995), and the same pattern has also been observed in other European lakes and reservoirs too (Wanzenböck et al. 1997; Tischler et al. 2000; Čech et al. 2005; Scharf et al. 2009). But what are the species composition and fry densities in late summer? Are they consistent from year to year? Are the biotic and abiotic factors such as food availability, water temperature or water level (flooded or not flooded terrestrial vegetation) at the time of spawning, and during development of the juveniles, responsible for enhanced or, conversely, lowered fry density in late summer?

2) to evaluate the spatial distribution of pelagic fry in the reservoir. Canyon-shaped reservoirs are distinct types of water bodies, when compared with natural lakes, with longitudinal and depth gradients as described above. The typical, narrowing towards the river inflow, shape of the canyon-shaped reservoir means that there are changes in the ratio of littoral and pelagic areas along its longitudinal profile. Because fish utilize both habitats alternately between day and night during their first year of life (Bohl 1980; Gliwicz \& Jächner 1992) it is probable that a changing ratio between littoral and pelagic areas can influence the pelagic fry density along the longitudinal profile of the reservoir at night.

3 ) to examine differences in the distributions of different fry species in the reservoir. Two cyprinid species, roach (Rutilus rutilus) and bream (Abramis brama) dominated the beach seine catches of adult fish during the period of our experiments, whereas percid species, perch (Perca fluviatilis), pikeperch (Sander lucioperca) and ruffe (Gymnocephalus cernuus), were a regular part of the catch but not so abundant (Říha et al. 2009). Differences have been found between roach and perch in their preference for eutrophic conditions (Jeppesen et al. 2000) and in their efficiency in capturing zooplankton under different temperature conditions (Persson 1986). Only the canyon-shaped reservoirs present both the characteristics mentioned - change of trophic status along the longitudinal profile and change of the temperature conditions in the vertical (depth) profile of the reservoir and, therefore, different spatial distributions of roach and perch fry can be expected in such water bodies.

\section{MATERIAL AND METHODS}

\subsection{Study area}

The study was carried out in the canyon-shaped Rímov Reservoir (Fig. 1), a narrow, deep, man-made lake in South Bohemia, Czech Republic. The dam was built in 1978 on the Malše River and Rímov Reservoir serves as drinking water storage for the South Bohemian region. Its surface area is 210 ha, volume $33.10 \times 10^{6}$ $\mathrm{m}^{3}$, length $12 \mathrm{~km}$ and the maximum surface elevation is $471 \mathrm{~m}$ a.s.l. The mean depth of the reservoir is $16 \mathrm{~m}$, the maximum depth $45 \mathrm{~m}$ and the theoretical retention time is 95 days. Ŕimov Reservoir is dimictic and the typical thermocline depth is about 4-5 $\mathrm{m}$ in August. The oxygen concentrations usually varied between $7-9 \mathrm{mg} \mathrm{L}^{-1}$ in the surface water stratum between $0-3 \mathrm{~m}$. In deeper strata (below $4 \mathrm{~m}$ ) oxygen concentrations is usually lower than $4 \mathrm{mg} \mathrm{L}^{-1}$ in August (Draštík et al. 2008). The trophic status of the reservoir can be characterized as moderately eutrophic to eutrophic with both phosphorus and chlorophyll- $a$ concentrations decreasing downstream (Sed'a \& Devetter 2000).

\subsection{Data collection and analysis}

\subsubsection{Fry sampling}

Trawling for fry was carried out in the late summer (mid-August) from 1999 to 2006, except for 2002 when 
unusually high flooding prevented sampling in the reservoir. The reservoir was divided into three areas along its longitudinal axis (Fig. 1), referred to as the dam, middle and upper areas, each of which represented approximately one third of the reservoir length (according to Vašek et al. 2006). The exact sampling transects along this longitudinal profile are shown in figure 1 (10 localities).

Three depth strata were sampled in all years: the surface water layer between 0-3 m, deeper strata between 3-6 $\mathrm{m}$ (4-7 $\mathrm{m}$ in 1999), and at 6-9 $\mathrm{m}$. The total number of tows was 81 ). In every year all available depth horizons, down to $9 \mathrm{~m}$, were sampled in all areas (Fig. 1). Tows in deeper, open water strata took place in the dam and middle areas only because the upper area is too shallow $(<4 \mathrm{~m})$ for safe pelagic trawling and therefore, comparisons of fry density between different depth strata could only be made for the dam and middle areas. Sampling in water deeper than $9 \mathrm{~m}$ was not necessary due to fish avoiding the de-oxygenated hypolimnion, which was confirmed using hydroacoustics during every sampling night (EY500 or EK60 split beam echosounders, Draštík et al. 2008). The mean water volume sampled by each tow, in each depth stratum, was $5400 \mathrm{~m}^{3}$ and there was almost no variation of water volume sampled between years and water strata.

The reservoir was also divided horizontally, representing the littoral and pelagic zones along the three longitudinal areas. The water volumes of the littoral and pelagic zones in each of the three longitudinal areas were calculated from a digital three-dimensional bathymetric model using GIS technologies (software: ArcGIS - ESRI, Geomatica - PCI Canada and Anudem) based on depth, length and width data for the particular reservoir section. The littoral to open water volume ratios were compared for all three longitudinal areas (upper/middle; upper/dam; middle/dam). In the dam and middle areas of the reservoir the volume was calculated for the $0-5 \mathrm{~m}$ water stratum (i.e., the extent of the epilimnion) while in the upper area the volume of the 0 $3 \mathrm{~m}$ water layer was calculated for both the littoral and open water zones because there was insufficient depth in that area to include a 0-5 m layer. With these comparisons we obtained numbers such as, how many times greater are the littoral/open water ratios in the upper area than in the middle and dam areas (or in the middle area than in the dam area). These calculations of litto$\mathrm{ral} /$ open water ratios were made for different years separately to take into account between year variations in reservoir level.

A pelagic, fixed-frame fry trawl (mouth opening $3 \times 3$ $\mathrm{m}$, length $5.4 \mathrm{~m}$, mesh size $6 \mathrm{~mm}$ in the belly, $3 \mathrm{~mm}$ in the cod end) was used to sample the fry. The $3 \mathrm{~mm}$ mesh size in the cod end was small enough, with regard to the size of the fry in late summer, to ensure that fry were not able to escape through the meshes of the trawl (the smallest were usually fry of ruffe and bleak whose smallest individuals were $\geq 35 \mathrm{~mm}$ ). The trawl was also equipped with a funnel made of netting to prevent fish from escaping (Jůza \& Kubečka 2007). In all years, trawling was conducted at night, when the light intensity was below 1 lux and during calm weather. No trawling was done during a full moon.

Sampling depth of the fry trawl was regulated with a polystyrene floater attached to the upper part of the frame. The length of the rope between the frame and the floater kept the trawl at the required depth. The lower part of the trawl frame was equipped with two iron sledges to weight it, and to reduce contact of the trawl with the bottom. Trawls were towed approximately 100 $\mathrm{m}$ behind the boat, usually for 10 minutes, at velocities of $0.8-1.1 \mathrm{~m} \mathrm{~s}^{-1}$. The trajectory of the trawl during deployment was generally out of the boat's wake and the fish were thus captured outside the directly disturbed area. The volume of water sampled was calculated for each haul (see Jůza \& Kubečka 2007). In 1999-2001, a flat-bottomed boat, powered by a $25 \mathrm{hp}$ outboard engine was used for trawling while, in 2003-2006 the research vessel Ota Oliva (64 hp diesel engine, Kubečka et al. 2003) was used as the trawler.

All the juvenile fish from each trawl tow were immediately preserved in $4 \%$ formaldehyde. In the laboratory, the fish were identified and counted. Catch was expressed in terms of density (number of fish per 100 $\mathrm{m}^{3}$ of water sampled).

\subsubsection{Zooplankton sampling}

Zooplankton was collected at a station near the dam during the day at three-week intervals from May to October during the 7-year study. Samples were taken by vertical hauls from the bottom to the surface with an Apstein plankton net (mouth diameter $20 \mathrm{~cm}$, mesh size $200 \mu \mathrm{m}$ ). At least two hauls were combined to make one sample, which represented a sampled volume of $c a$ 2200 liters, but the zooplankton biomass data were recalculated per square metre of lake surface. The samples of live zooplankton were divided into three size fractions using sieves with meshes of 0.71 and $0.42 \mathrm{~mm}$ (Sed'a \& Dostálková 1996). The biomass of the zooplankton size fractions was measured as protein nitrogen using the Biuret reaction (Blažka 1966). For investigation of the relationship between zooplankton biomass and fry density only zooplankton retained by the $0.71 \mathrm{~mm}$ sieve was used, because this size fraction, which consisted almost entirely of large cladocerans (Daphnia, Leptodora), contained the main dietary components of the dominant species of fry in Ř́mov Reservoir during late summer (Vašek et al. 2006). Note that nearly all the zooplankton biomass, although expressed per square metre, was actually concentrated in the upper $5 \mathrm{~m}$ layer in the 40 meters deep reservoir during the summer (Sed'a et al. 2007). 


\subsubsection{Biotic and abiotic factors}

To investigate the potential impact of fry in the surface stratum on the mean July and August zooplankton community, we focused on two statistical relationships: (1) fry density in the surface stratum of the dam area only and the biomass of large-sized cladocerans in the same area and (2) fry density in the surface stratum of the whole reservoir (mean across the entire reservoir) and mean biomass of large-sized cladocerans in the dam area. Zooplankton biomass in June and August only was used because earlier in the year fry are too small to feed on large cladocerans, hence they are not able to influence their biomass (Hansson et al. 2007).

Abiotic factors such as water temperature and water level exactly at the time of spawning of cyprinid fish and mean water level in the period from May to August (measured daily) were recorded. Interannual data on water temperatures and water levels were obtained from the databank of the Institute of Hydrobiology in České Budějovice.

\subsubsection{Statistical analysis}

For testing differences of surface fry density (1) in three areas along the longitudinal axis (dam, middle, upper), (2) in different water strata (0-3 m, 3-6 m, 6-9 $\mathrm{m})$ and (3) interannual differences, a one-way analysis of variance (one-way ANOVA; Statistica software) was performed. The influence of the independent variable (year) in year to year comparisons was analyzed by the post-hoc Tukey HSD test. The null hypothesis assumed that there were no differences in fry density among areas (longitudinal profile), among water strata (vertical profile) and among the seven years investigated. Statistical relationships between fry density and biotic and abiotic factors were modeled by multiple regression (Statistica software).

Direct gradient redundancy analysis (RDA; Canoco for Windows 4.5 software; Lepš and Šmilauer 2003) was used to evaluate the species composition in different years, species preference for the three areas (dam, middle, upper) along the longitudinal profile and species depth preferences. Affiliations to each year, sampling area (dam, middle, upper) and depth strata (0-3, 3-6, 6-9 $\mathrm{m})$ were assigned as dummy variables in the analysis. Data were log-transformed

$$
\mathrm{y}^{\prime}=\log (\mathrm{y}+1.5)
$$

centered by species and scaling was focused on interspecies correlations: species scores were divided by the standard deviation. The significance of the relationship between species composition data and selected spatial profiles (longitudinal and vertical) was tested by the Monte Carlo permutation test (Canoco for Windows 4.5 software).

A contour map was used as the general model of the cyprinid and percid fry distributions (Surfer software, version 2002). For the Surfer software, data entered were assigned as numbers 1-9.5 (see Fig. 1) for the locality ( $\mathrm{x}$ axis), 1.5; 4.5 and 7.5 (mean depths of the strata sampled) for water depth (y axis) and the percentage value of the maximal fry density (the locality with highest observed density in the appropriate year was assigned as $100 \%$ and the percentage values of the remaining localities and depths sampled were recalculated proportionally for that year). Data from all ten localities and water depths were averaged over all years for the model. Two localities in the upper area of the reservoir (9 and 10; see Fig.1) were entered as locality 9.5 into the Surfer model with the mean value from both localities. The reason for this integration was the smaller number of trawl tows made in locality 10, which was due to low water levels in some years. The percentage fry density in locality 9 was assigned to locality 9.5 in the event that there was no trawl tow in locality 10 in that year. Kriging was used as the gridding method. The isoline numbers in the Surfer model conformed to the mean percentage density (over all years) in the relevant locality and relevant depth stratum, recalculated from the area with the highest fry density (given as $100 \%$ in particular years) computed by the Surfer software.

\section{RESULTS}

\subsection{Species composition and density of open water fry}

During the seven year study, 7006 juvenile fish, belonging to 10 species, plus a bream-roach hybrid, were captured in 81 tows. In all years, cyprinids dominated the pelagic samples in the surface water (Fig. 2). Roach (Rutilus rutilus) was the most abundant species in 1999, 2004 and 2005, in 2001 and 2003 bream (Abramis brama) was dominant. The third most abundant cyprinid species overall was bleak (Alburnus alburnus), which was most numerous in 2000 and 2006. Catches of other cyprinids, dace (Leuciscus leuciscus) and asp (Aspius aspius) were rare. Although cyprinids consistently dominated the pelagic fry catches in the reservoir, percid fry were also an important component, but more variable. In 2004 pikeperch fry (Sander lucioperca) and in 1999, 2001 and 2005 perch fry (Perca fluviatilis) were the second most abundant species after roach or bream. Less common species in the open water area were ruffe (Gymnocephalus cernuus), catfish (Silurus glanis) and gudgeon (Gobio gobio). RDA analysis with the best fit, in which six dominant species ( 3 cyprinids and 3 percids) from all sampled depths were included, also revealed significant differences $(F=7.1 ; p=0.002)$ in species composition between years.

The highest fry density was observed in 1999 and the lowest in 2000. Whereas the mean density in 1999 in the surface water layer reached 15 ind $100 \mathrm{~m}^{-3}$, the mean density in the same stratum in 2000 was only 0.1 ind $100 \mathrm{~m}^{-3}$. Mean density in the remaining years varied between 0.9 and 3.6 ind $100 \mathrm{~m}^{-3}$ (Fig. 3). Interannual fry densities differed significantly when we compared all 


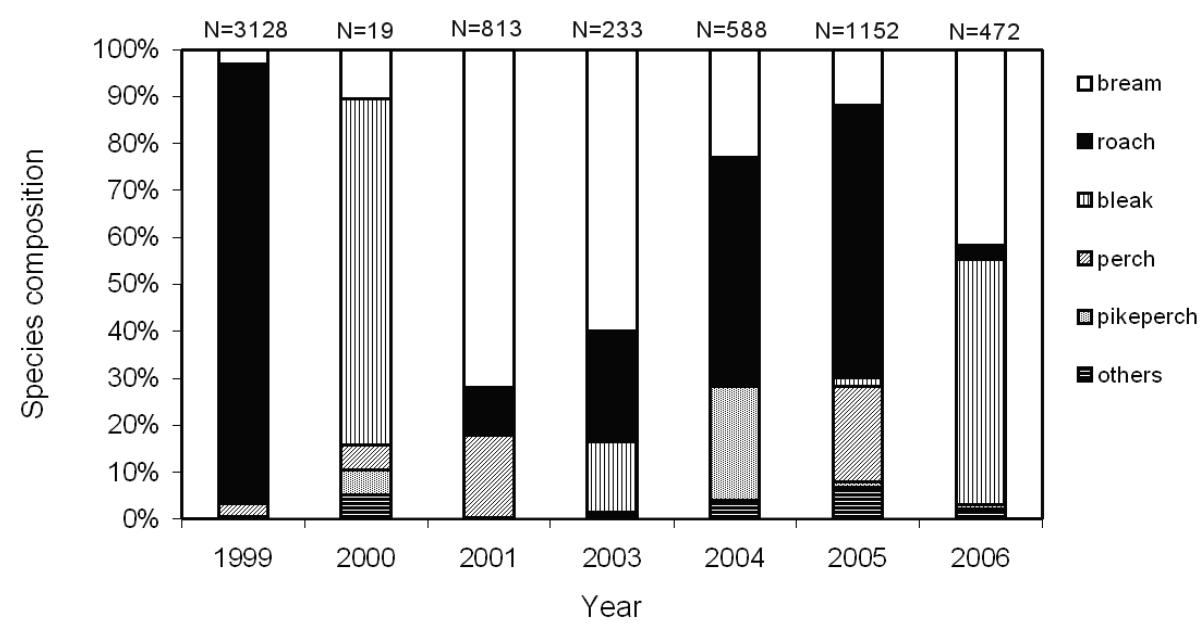

Fig. 2. Species composition of fry in the surface water layer (0-3 m depth) in different years in Řimov Reservoir. Numbers above each column mean the total number of fish captured in the surface water (0-3 m) in that year regardless of the number of trawl tows in that year.

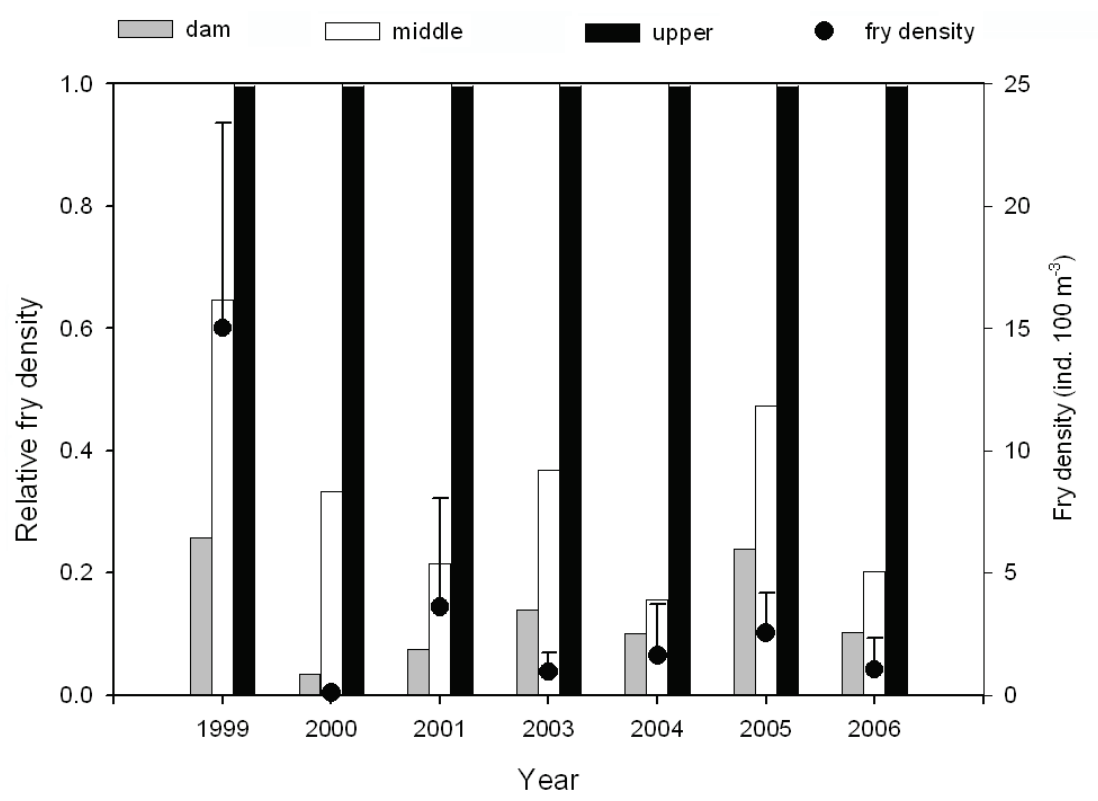

Fig. 3. Comparison of fry densities (mean + S.D. along whole longitudinal transect) in the surface water stratum of Rímov Reservoir in different years together with relative densities of fry in different years among three localities along the longitudinal profile of Ŕímov Reservoir in the surface water stratum (0-3 m). Density in the upper area was set to 1 and densities in the remaining two localities were recalculated as relative proportions.

years $\left(F=11.4 ; p<10^{-6}\right)$ but the post-hoc Tukey HSD test revealed that this significance was caused by the elevated fry density in 1999. Density in that year was significantly different from all the other years, whereas there were no significant differences observed between the other years.

Several biotic and abiotic factors were considered to explain the variable fry densities. The effect of food availability on the strength of year classes was determined from the relationships between the biomass of large cladocerans and fry density in the surface layer. Because the zooplankton was sampled only at the dam area, for this purpose we used the fry data from the dam area only. However, this correlation was not significant (July-August; $R=0.05 ; p=0.91$ ). Similarly there were no significant correlations $(R=0.01 ; p=0.98)$ between the same zooplankton data and the fry densities from the whole reservoir (mean across the entire longitudinal profile). We observed a non-significant correlation between August cyprinid fry density and mean water temperature at the time of spawning of roach, bream and bleak $(R=0.55 ; p=0.25)$ and the effect of water level in the spawning period also had no significant correlation with the August density of cyprinid fry $(R=0.17 ; p$ $=0.71$ ). The regression between mean water level in the period from May to August and fry density in August 
Tab. 1. Correlation parameters of dominant fish species density and four biotic and abiotic factors. Two abiotic factors connected with the exact time of spawning were investigated for cyprinid fish only.

\begin{tabular}{c|cccccc}
\hline Factor & Roach & Bream & Bleak & Perch & Pikeperch & All species \\
\hline Water temperature in time of & $p=0.37$ & $p=0.84$ & $p=0.69$ & & & $p=0.25$ \\
spawning & $R=0.19$ & $R=0.09$ & $R=0.19$ & & & $R=0.55$ \\
& $p=0.83$ & $p=0.25$ & $p=0.31$ & & & $p=0.71$ \\
Water level in time of spawning & $R=0.10$ & $R=0.49$ & $R=0.45$ & & & $R=0.17$ \\
Water level in the period May - & $p=0.58$ & $p=0.60$ & $p=0.88$ & $p=0.87$ & $p=0.30$ & $p=0.51$ \\
August & $R=0.26$ & $R=0.24$ & $R=0.07$ & $R=0.07$ & $R=0.46$ & $R=0.31$ \\
Large cladocerans biomass in the & $p=0.09$ & $p=0.66$ & $p=0.11$ & $p=0.83$ & $p=0.65$ & $p=0.98$ \\
same year (July - August) & $R=0.04$ & $R=0.19$ & $R=0.65$ & $R=0.10$ & $R=0.21$ & $R=0.01$ \\
\hline
\end{tabular}

was slightly positive but, again, not significant $(R=$ $0.31 ; p=0.51)$.

Correlations between density of each fry species and the biotic and abiotic factors named above were also investigated. Similarly, there were no statistically significant correlations (Tab. 1).

\subsection{Distribution of fry along the longitudinal and vertical profiles of the reservoir}

The density of fry varied considerably along the longitudinal profile of the reservoir. In all the years investigated, the highest fry density was observed in the upper area and declined considerably towards the dam, where catches were smallest (Fig. 3). For this comparison, the density in the upper area was set to 1 for all years and densities in the other two localities were recalculated as ratios in order to eliminate betweenyears density differences. The one-way ANOVA of 1999-2006 data from the dam, middle and upper areas indicates that total fish density in the surface stratum differed significantly between the three areas $(F=3.85$; $p=0.029$ ). The mean 1999-2006 density \pm SD was 0.95 $\pm 1.45,3.01 \pm 4.79$ and $6.6 \pm 7.22$ ind $100 \mathrm{~m}^{-3}$ in the dam, middle and upper areas, respectively. RDA analysis also revealed statistically significant differences $(F=$ 4.33; $p=0.004)$ in species preferences for particular areas along the longitudinal profile of the reservoir (Fig. $4 a)$. The two dominant families were clearly separated: the abundance of dominant cyprinid fish was highest in the upper area, whereas percid fish preferred the middle area of the reservoir. Area (dam, middle, upper) as an environmental variable explained $11.8 \%$ of the total variation of species composition data.

The mean (over all years) littoral/open water volume ratios were 1.77 for the middle area/dam area (i.e. a 1.77 times larger volume ratio of littoral/open water in the middle area than in the dam area), 4.1 for the upper area/middle area and 7.27 for the upper area/dam area (Tab. 2). Table 2 shows the ratios of open water fry densities between areas (middle/dam, upper/middle, upper/dam) for all the years sampled except 2000 (densities in that year were too low for comparison). It is evident that the mean values of the ratios (across all years), of open water fry density between areas, are closely similar to the ratios of littoral volume/open water volume between the same areas.
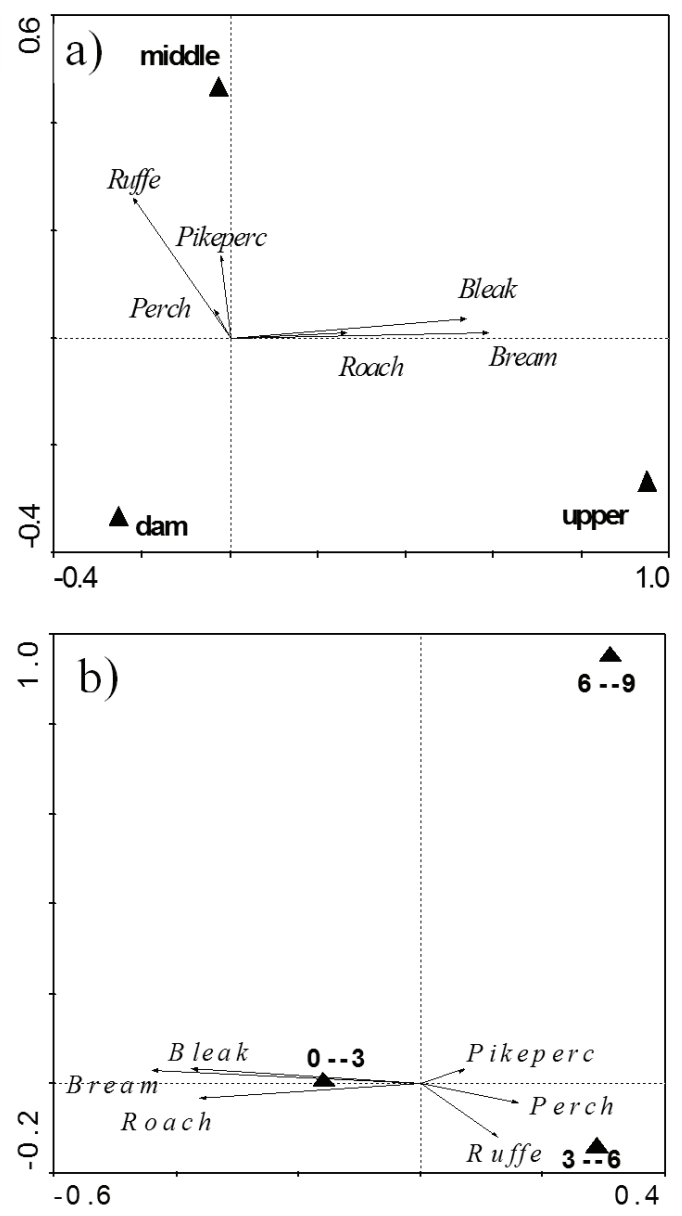

Fig. 4. Biplots of fry densities in the Rímov Reservoir from RDA analysis. Triangles denote centroids of each area along the longitudinal reservoir profile (a) and of each stratum in the vertical profile of the reservoir (b). Species arrows pointing in the same direction correspond to species that are predicted to have a large positive correlation, whereas species with a large negative correlation have arrows pointing in opposite directions.

The densities of fry were heterogeneously distributed over the vertical (depth) profile of the reservoir. 
However, the differences in total fry densities between different depth strata (averaged for the dam and middle areas) were not statistically significant $(F=0.42 ; p=$ 0.66 ; means $( \pm \mathrm{SD})$ of all species over all years $0-3 \mathrm{~m}-$ $2.5 \pm 4.67 ; 3-6 \mathrm{~m}-1.8 \pm 3.89 ; 6-9 \mathrm{~m}-0.01 \pm 0.02$ ind $\left./ 100 \mathrm{~m}^{-3}\right)$. The highest total fry density was observed in the surface water layer $(0-3 \mathrm{~m})$, in all years investigated except 2001, when the highest fry density was observed in the 3-6 m layer.

Tab. 2. The mean (over all years) littoral/open water volume ratios between three areas (dam, middle, upper) of the Rímov Reservoir and the ratios of open water fry densities in the surface water stratum between the three reservoir areas in different years. The year 2000 is not included because densities in that year were too low for comparison.

\begin{tabular}{cccc}
\hline \multirow{2}{*}{ Year } & \multicolumn{3}{c}{ Ratios of fry density } \\
\cline { 2 - 4 } & Middle/Dam & Upper/Middle & Upper/Dam \\
\hline \multirow{2}{*}{1999} & 2.5 & 1.6 & 3.9 \\
2001 & 2.9 & 4.6 & 13.3 \\
2003 & 2.6 & 2.7 & 7.2 \\
2004 & 1.5 & 6.4 & 9.9 \\
2005 & 2.0 & 2.2 & 4.2 \\
2006 & 2.0 & 4.9 & 9.7 \\
Mean & 2.3 & 3.7 & 8.0 \\
\hline \multicolumn{4}{c}{ Ratio of littoral/open water volumes } \\
\cline { 2 - 4 } & Middle/Dam & Upper/Middle & Upper/Dam \\
\hline \multicolumn{4}{c}{ 1.8 } \\
\hline
\end{tabular}

Years with higher or comparable fry densities in the 3-6 m layer, compared to the surface stratum, were characterized by a high density of perch fry in the open water. RDA analysis separated percid fry from cyprinid fry along the vertical profile and differences in species composition were statistically significant $(F=3.91 ; p=$ 0.006 ). Depth as an environmental variable explained $10.7 \%$ of the total variation of the species composition data. While cyprinid fish were almost entirely confined to the surface water, percids dominated at 3-6 m (Fig. 4b). Catches of any fry in the deepest stratum sampled (6-9 m) were only sporadic.

The dominance of cyprinid fry in the upper reservoir area and in the surface waters and the more uniform distribution of percid fry along the longitudinal and vertical profiles of the Rímov Reservoir were accurately modeled by the Surfer general models of fish fry distributions (Fig. 5). The highest density of cyprinid fish fry was revealed by Surfer to be in the upper area of the reservoir (Fig. 5a). Percid fish had apparently two maxima of occurrence in the lacustrine area of the reservoir. One was situated in the surface layer just slightly downstream from the maxima of cyprinid fish while the second maximum was situated on the boundary of the dam and middle areas of the reservoir at depths between 3 and 6 meters (Fig. 5b).

\section{DISCUSSION AND CONCLUSIONS}

\subsection{Interannual differences in species composition and densities of fry and the influence of biophysical factors}

This study has demonstrated that, in all the years investigated, fry of cyprinid fish dominated in the trawl catches and this corresponds to the species composition of adult fish. Cyprinid fish abundance increased after 1989, as perch abundance declined in the Římov Reservoir (Sed'a \& Kubečka 1997). Three cyprinid species (roach, bleak and bream) occurred most frequently in gillnets catches (Vašek et al. 2004) and this corresponds with the phase of ageing of the reservoir, which leads up to the stable cyprinid fish phase (Kubečka 1993; Říha et al. 2009).

The densities of the pelagic fry community were variable between years (Fig. 3). Year to year comparison of fry density in the open water revealed two extreme years. The highest fry density was observed in 1999 while the lowest, in 2000, was, on average, 150 times lower. In the other years the between-year fluctuations were relatively stable with a maximum threefold difference from year to year. Besides quantitative differences, high species fluctuations were also recorded.

We have taken several abiotic factors into account to try to explain these interannual differences. Water temperature at the time of spawning and during the larval period can influence survival of fish larvae (Grenouillet et al. 2001) and could explain the higher fry density in August. High water levels coinciding with the time of spawning means the presence of flooded terrestrial vegetation and therefore the availability of suitable spawning substrates for litho-phytophylic dominant cyprinid fish and higher water levels during the period of fry development (May-August) can lead to higher survival rates of fry due to the presence of flooded terrestrial vegetation, which provides the refuges from predation. All these abiotic factors were analyzed in relation to the fry density in August, because they were thought to be able to influence the August fry density significantly. However, neither temperature nor water level was significantly correlated with fry density in August. A large decline in water level after spawning could potentially have caused drying of hatching larvae, but we did not observe this in any year.

The main biotic factor affecting fry density in any one year was expected to be food availability. However, the fry densities were not significantly correlated to either high density of zooplankton (no bottom-up effect), nor to low density of zooplankton (no top-down effect). Young of the year fish (YOY), as the most abundant planktivores, have often been considered to be a major factor affecting the size and abundance of zooplankton in lakes (van Densen \& Vijverberg 1982; Cryer et al. 1986; Vijverberg et al. 1990; Romare \& Bergman 1999). However, in the Rímov Reservoir, 

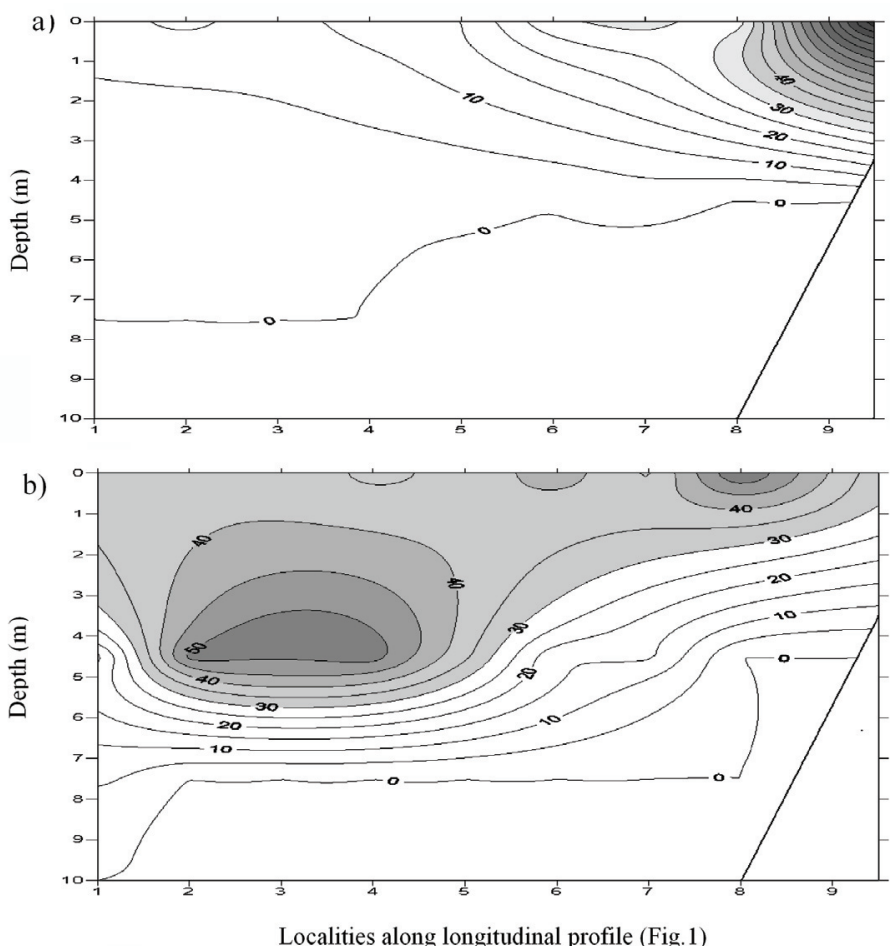

Fig. 5. General model of the distribution of cyprinid (a) and percid (b) fish fry in Rímov Reservoir. The isoline numbers in the Surfer's model conform to mean percentage density (over all years) in the relevant locality and relevant depth layer recalculated from the area with the highest fry density (given as $100 \%$ in a particular year). Localities 9 and 10 have been integrated together. The straight inclined line is the bottom of the reservoir.

there was no apparent relationship between the biomass of large cladocerans and fry densities in the dam area nor in the whole reservoir. The absence of significant correlations between the zooplankton biomass and whole reservoir fry densities, however, might be disputable because we have shown that there were significant differences in fry densities between dam-middle and upper reservoir areas and significant differences in zooplankton densities between these areas were found earlier (Sed'a \& Devetter 2000). However, the nature of horizontal variability of the zooplankton in Rímov Reservoir has shown that the differences between the stations along the longitudinal reservoir profile usually disappear when we compare seasonal averages (J. Sed'a, unpubl.). We feel that the lack of significant correlations between fry density and biomass of large-sized cladocerans was demonstrated by the absence of any zooplankton community response during two extreme years of fry abundance, 1999 (highest abundance) and 2000 (lowest abundance). We assume that even the high fry density $\left(15\right.$ individuals per $100 \mathrm{~m}^{3}$ ) in 1999 might be insufficient to significantly influence zooplankton community structure because, besides YOY fish, older juveniles and adult fish were also found to occupy the reservoir epilimnion in densities up to several individuals per $100 \mathrm{~m} 3$ (estimation based on the data from Draštík et al. 2008; 2009 and unpublished data of J. Kubečka). These older juvenile and adult fish (dominated by roach, bream and bleak) also fed mostly on zooplankton (Vašek et al. 2003) having much higher absolute daily food intakes than YOY fish (Vašek \& Kubečka 2004). In such a situation the zooplankton dynamics are not driven purely by the YOY fish abundance. Instead, older fish seem to be an important factor for shaping the zooplankton community and zooplanktivory of older fish should not be overlooked in future biological studies.

As described above, the chosen biotic and abiotic factors were not correlated with the fry density in August. What other reason can therefore be, especially for the extremely high fry density in 1999? Night trawling with a $3 \times 3 \mathrm{~m}$ trawl in late summer was recommended for quantitative sampling (Jůza \& Kubečka 2007) so this method is a representative measure of fry densities and the variation in densities was not an artefact of sampling. We can hypothesize that in 1999 a period of high fry densities came to an end, because before this year the period of high abundance of adult roach in the reservoir ended (Číha et al. 2009) and from this year onward fry density was stable and relatively low. This theory is supported by the species composition of the fry, because in 1999 the catch consisted almost exclusively of roach. Besides the fluctuations in fry density large fluctuations in species composition were also observed between all the years investigated. In 2000 almost no fry were present in the open water area of Rímov Reservoir and in 2006 bleak dominated. In all the remaining years roach and bream varied in 
dominance. Bream and roach strongly dominated the beach seine catches in 1999-2006 and the dominance between these two species was changeable too (Říha et al. 2009). The proportion of adult percid species in these beach seine catches was relatively stable and much lower than the proportion of cyprinids throughout this period (Říha et al. 2009), however we did not observe years with enhanced proportions of percid fry (perch, pikeperch) in night trawl catches. Longer data series will therefore be necessary in order to understand the possible cycling of fry species in the open water of the reservoir.

\subsection{General distribution of fry in the reservoir}

The highest densities of fry were observed in the upper area of the reservoir in all years of our study. This finding is in agreement with earlier observations using hydroacoustics or gillnetting (Fernardo \& Holčík 1991; Brosse et al. 1999; Araújo \& Santos 2001; Vašek et al. 2004; Draštík et al. 2008). There are several hypotheses to explain the higher fry density in the upper area of the reservoir. Firstly, the ichthyofauna of the reservoir is composed of species of riverine origin, which may not be completely adapted to lacustrine conditions and prefer shallow inshore areas at the river mouth of the reservoir (Fernando \& Holčík 1991). Secondly, higher fry density in the upper area may reflect higher production compared with downstream areas (Lind et al. 1993). Thirdly, a combination of the ratio of the shoreline length to the volume of a particular area of a reservoir, in combination with the diurnal migration of fry between inshore and offshore areas, could be another possibility (Vašek et al. 2004). Many YOY fish spend the daytime in the littoral zone and at dusk move to the open water (Bohl 1980; Gliwitz \& Jächner 1992), which may be caused by a higher risk of predation in pelagic zones by day and the greater food availability in the pelagic zone. Assuming a constant density of fry per unit of shore length or the volume of the littoral zone, night-time fry density in the open water should be higher in the narrower, upper area of the reservoir in comparison with the wider downstream areas (Vašek et al. 2004). The different volume ratios of the litto$\mathrm{ral} /$ open water zones in the three areas of the longitudinal profile could thus explain the highest fry density found in the narrow upper area. Indeed, a positive correlation between the proportion of littoral zone and fry density was found in this study. When we compared the littoral/open water ratios between different reservoir areas we found that these ratios were similar to the proportions of the open water fry densities between these areas. Our results therefore suggest that the highest fry density in the upper area during the night was a consequence of the high ratio of littoral/open water zone in this part of the reservoir. Biological factors have often been considered to be the main reasons for the higher densities of YOY and adult fish in the upper areas of canyon-shaped reservoirs. Our results suggest, however, that the morphology of this type of reservoir (gradient of the relative volumes of littoral) is responsible for the different patterns of YOY distribution, i.e. higher concentrations of YOY fish in the narrower, upper part of the reservoir. It seems that the effect of reservoir morphology may mitigate the potential effects of other limiting biotic and abiotic factors.

Sharp gradients in the oxygen content, food availability and temperature in the metalimnion determine the vertical distribution of fish in lakes (Järvalt et al. 2005). In artificially destratified, deep reservoirs fish inhabited the whole volume (Prchalová et al. 2006). In the sharply stratified Rímov Reservoir the highest fry density was usually observed in the surface layer as has also been observed for adult fish in other stratified lakes and reservoirs (Vašek et al. 2004; Järvalt et al. 2005; Kahl \& Radke 2006; Prchalová et al. 2008).

\subsection{Distribution of different fry species in the reservoir}

The distribution of fry in both longitudinal and vertical reservoir profiles reflected habitat partitioning among the dominant families. Along the longitudinal profile, cyprinid fish always strongly dominated in the upper area, whereas the abundance of percid fish was highest in the middle area. Cyprinids strongly dominated in the surface stratum (0-3 m depth) whereas percids dominated catches around the thermocline (3-6 m depth). Perch usually prefer clean-water lakes (Järvalt et al. 2005), while cyprinids, including roach, are known to thrive under more eutrophic and turbid conditions (Jeppesen et al. 2000). This could be an explanation for the dominance of roach and other cyprinid fish in the turbid and more eutrophic upper area of Římov Reservoir, whereas percid fish prefer the less eutrophic middle area of the reservoir. Another explanation for the highest abundance of cyprinid fry being in the upper area may be related to adult spawning migrations. Because cyprinids were the most abundant fish species migrating to the tributary of the Rímov Reservoir (Hladík \& Kubečka 2003) it is likely that the cyprinid fry stay in the upper and tributary areas in their first year of life.

The reason for the vertical segregation of cyprinid and percid fish could be related to species-specific feeding efficiencies at different temperatures. Perch have a greater efficiency of capturing zooplankton at temperatures below $18{ }^{\circ} \mathrm{C}$, while roach are more efficient in capturing zooplankton at temperatures exceeding $18{ }^{\circ} \mathrm{C}$ (Persson 1986) and the optimal temperature for growth of roach lies between 20 and $27^{\circ} \mathrm{C}$ (van Dijk et al. 2002). Roach in the Rímov Reservoir thus preferred the surface water where the temperature was highest. The segregation of perch and roach along the temperature gradient in the pelagic zone was probably a result of selecting their optimal temperatures with respect to species-specific foraging efficiency and growth (Kahl \& Radke 2006). 


\section{ACKNOWLEDGMENTS}

We thank Z. Prachař for help with data collection, Dr. V. Tereschenko for critical reading of the manuscript, Mary Burgis and David MacNeill (NY Sea Grant Program) for careful reading and editing the English and two anonymous referees for helpful comments on the manuscript. The work was supported by the project 1QS600170504 and AVOZ 60170517 of ASCR and 206/07/1392, 206/06/1371 and 206/06/P418 of GACR.

\section{REFERENCES}

Araújo, F.G. \& L.N. Santos. 2001. Distribution of fish assemblages in Lajes Reservoir, Rio De Janeiro. Braz. J. Biol., 61: $563-576$.

Blažka, P. 1966. Bestimmung der Proteine im Material aus Binnengewassern. Limnologica, 4: 387-396.

Bohl, E. 1980. Diel pattern of pelagic distribution and feeding in planktivorous fish. Oecologia, 44: 368-375.

Brosse, S., F. Dauba, T. Oberdorff \& S. Lek. 1999. Influence of some topographical variables on the spatial distribution of lake fish during summer stratification. Arch. Hydrobiol., 145: 359-371.

Copp, G.H. \& P. Jurajda. 1993. Do small riverine fish move inshore at night? J. Fish Biol., 43: 229-241.

Cryer, M., G. Peirson. \& C.R. Townsend. 1986. Reciprocal interactions between roach, Rutilus rutilus, and zooplankton in a small lake: Prey dynamics and fish growth and recruitment. Limnol. Oceanogr., 31: 1022-1038.

Čech, M., M. Kratochvíl, J. Kubečka, V. Draštík \& J. Matěna. 2005. Diel vertical migrations of bathypelagic perch fry. $J$. Fish Biol., 66: 685-702.

Čech, M., J. Kubečka, J. Frouzová, V. Draštík., M. Kratochvíl, J. Matěna \& J. Hejzlar. 2007a. Distribution of bathypelagic perch fry layer along the longitudinal profile of two large canyon-shaped reservoirs. J. Fish Biol., 70: 141-154.

Čech, M., J. Kubečka, J. Frouzová, V. Draštík, M. Kratochvíl \& J. Jarošík. 2007b. Impact of flood on distribution of bathypelagic perch fry layer along the longitudinal profile of large canyon-shaped reservoir. J. Fish Biol., 70: 11091119.

Draštík, V., J. Kubečka, M. Tušer, M. Čech, J. Frouzová, O. Jarolím \& M. Prchalová. 2008. The effect of hydropower on fish stock: comparison between cascade and non-cascade reservoirs. Hydrobiologia, 609: 25-36.

Draštík, V., J. Kubečka, M. Čech, J. Frouzová, M. Říha, T. Jůza, M. Tušer, O. Jarolím, M. Prchalová, J. Peterka, M. Vašek, M. Kratochvíl, J.Matěna \& T. Mrkvička. 2009. Hydroacoustic estimates of fish stock in temperate reservoirs: day or night surveys? Aquat. Liv. Res., 22: 69-77.

Fernando, C.H. \& J. Holčík. 1991. Fish in reservoirs. Int. Rev. ges. Hydrobiol., 76: 149-167.

Fernándes-Rosado, M.J., J. Lucena \& F.X. Niell. 1994. Spacetime heterogeneity of the chlorophyll-a distribution in La Concepción Reservoir (Istán, Málaga). Representative models. Arch. Hydrobiol., 129: 311-325.

Fernándes-Rosado, M.J. \& J. Lucena. 2001. Space time heterogeneities of the zooplankton distribution in La Concepción Reservoir (Istán, Málaga; Spain). Hydrobiologia, 455: $157-170$.

Frankiewicz, P., K. Dabrowski \& M. Zalewski. 1996. Mechanism of establishing bimodality in a size distribution of age-0 pikeperch, Stizostedion lucioperca (L.) in the Sulejów Reservoir, Central Poland. Ann. Zool. Fenn., 33: 321327.

George, D.G. \& I.J. Winfield. 2000. Factors influencing the spatial distribution of zooplankton and fish in Loch Ness, UK. Freshwat. Biol., 43: 557-570.
Gliwicz, Z.M. \& A. Jächner. 1992. Diel migrations of juvenilie fish - a ghost of predation past or present? Arch. Hydrobiol. 124: 385-410.

Grenouillet, G.B., G.A. Hugueny, J. Carrel, M. Olivier \& D. Pont. 2001. Large-scale synchrony and inter-annual variability in roach recruitment in the Rhone River: the relative role of climatic factors and density-dependent process. Freshwat. Biol., 46: 11-26.

Hansson, L.A., A. Nicolle, J. Brodersen, P. Romare, P.A. Nilsson, C. Bronmark. 2007. Consequences of fish predation, migration, and juvenile ontogeny on zooplankton spring dynamics. Limnol. Oceanog., 52: 696-706.

Hejzlar, J. \& V. Vyhnálek. 1998. Longitudinal heterogenity of phosphorus and phytoplankton concentrations in deepvalley reservoirs. Internat. Rev. Hydrobiol., 83: 139-146.

Hladík, M. \& J. Kubečka. 2003. Fish migration between a temperate reservoir and its main tributary. Hydrobiologia, 504: 251-266.

Järvalt, A., T. Krause \& A. Palm. 2005. Diel migration and spatial distribution of fish in a small stratified lake. Hydrobiologia, 547: 197-203.

Jeppesen, E., J.P. Jensen, M. S ndergaard, T. Lauridsen \& F. Landkildehus. 2000. Trophic structure, species richness and biodiversity in Danish lakes: changes along a phosphorus gradient. Freshwat. Biol., 45: 201-218.

Jurajda, P., M. Reichard \& E. Hohausová. 1997. A survey of inshore 0+ juvenile fish community in the Nové Mlýny lowland reservoir, Czech Republic. Fol. Zool., 46: 279285.

Jůza, T. \& J. Kubečka. 2007. The efficiency of three fry trawls for sampling the freshwater pelagic fry community. Fish. Res., 85: 285-290.

Kahl, U. \& J. Radke. 2006. Habitat and food resource use of perch and roach in a deep mesotrophic reservoir: enough space to avoid competition? Ecol. Freshwat. Fish., 15: 4856.

Kubečka, J. 1993. Succession of fish communities in reservoirs of Central and Eastern Europe. In: Straškaraba M., Tundisi J., Duncan A. (Eds), Comparative reservoir limnology and water quality managament. Kluwer Acad. Publ.: 153-168.

Kubečka, J. \& M. Švátora. 1993. Abundance estimates of perch fry (Perca fluviatilis), complicated by grouped behaviour. Ecol. Freshwat. Fish., 2: 84-90.

Kubečka, J., J. Matěna \& J. Peterka. 2003. Vzorkování rybích obsádek volné vody údolních nádrží. Vodni hospodářství, 10: 273-275.

Lepš, J. \& P. Šmilauer. 2003. Multivariate analysis of ecological data using $C A N O C O$. Cambridge University Press, Cambridge: $282 \mathrm{pp}$.

Lind, O.T., T.T. Terrell \& B.L. Kimmel. 1993. Problems in reservoir trophic-state classification and implications for reservoir management. In: Straškraba, M., J.G. Tundisi and A. Duncan (Eds). Comparative reservoir limnology and water quality managament. Kluwer Academic Publishers, The Netherlands: 55-67.

Macháček, J. \& J. Matěna. 1997. Diurnal feeding patterns of age-0 perch (Perca fluviatilis) and roach (Rutilus rutilus) in a steep-sided reservoir. Arch. Hydrobiol., Spec. Iss. Adv. Limnol., 49: 59-70.

Masson, S., N. Angeli, J. Guillard \& B. Pinel-Alloul. 2001. Diel vertical and horizontal distribution of crustacean zooplankton and young of the year fish in a sub-alpine lake: an approach based on high frequency sampling. J. Plankton Res., 23: 1041-1060.

Matěna, J. 1995. Ichtyoplankton and 0+ pelagic fish in the Ŕímov reservoir (Southern Bohemia). Fol. Zool., 44: 3143.

Mills, E.L. \& J.L. Forney. 1983. Impact on Daphnia pulex of predation by young yellow perch in Oneida Lake, New York. Trans Am. Fish. Soc., 112: 151-161. 
Okun, N. \& T. Mehner. 2005. Distribution and feeding of juvenile fish on invertebrates in littoral reed (Phragmites) stands. Ecol. Freshwat. Fish., 14: 139-149.

Okun, N., W.C. Lewin \& T. Mehner. 2005. Top-down and bottom-up impacts of juvenile fish in a littoral reed stand. Freshwat. Biol., 50: 798-812.

Oliveira, E.F., E. Goulart \& C.V. Minte-Vera. 2004. Fish diversity along spatial gradients in the Itapu Reservoir, Paraná, Brazil. Braz. J. Biol., 64: 447-458.

Persson, L. 1986. Temperature-induced shift in foraging ability in two fish species, roach (Rutilus rutilus) and perch (Perca fluviatilis): implications for coexistence between poikilotherms. J. Anim. Ecol., 55: 829-839.

Prchalová, M., J. Kubečka, M. Hladík, E. Hohausová, M. Čech \& J. Frouzová. 2006. Fish habitat preferences in an artificial reservoir system. Verh. Int. Ver. Limnol., 29: 1890-1894.

Prchalová, M., J. Kubečka, M. Vašek, J. Peterka, J. Sed’a, T. Jůza, M. Ríha, O. Jarolím, M. Tušer, M. Kratochvíl, M. Čech, V. Draštík, J. Frouzová \& E. Hohausová. 2008. Distribution patterns of fishes in a canyon-shaped reservoir. J. Fish Biol., 73: 54-78.

Prchalová, M., J. Kubečka, M. Čech, J. Frouzová, V. Draštík, E. Hohausová, T. Jůza, M. Kratochvíl, J. Matěna, J. Peterka, M. Ŕíha, M. Tušer \& M. Vašek. 2009. The effect of depth, distance from dam and habitat on spatial distribution of fish in artificial reservoir. Ecol. Freshwat. Fish., 247-260.

Romare, P. \& E. Bergman. 1999. Juvenile fish expansion following biomanipulation and its effect on zooplankton. Hydrobiologia, 404: 89-97.

Rudstam, L.G., A.J. VanDeValk \& M.D. Scheuerell. 2002. Comparison of acoustic and Miller high-speed sampler estimates of larval fish abundance in Oneida Lake, New York. Fish. Res., 57: 145-154.

Ř́ha, M., J. Kubečka, M. Vašek, J. Sed’a, T. Mrkvička, M. Prchalová, J. Matěna, M. Hladík, M. Čech, V. Draštík, J. Frouzová, E. Hohausová, O. Jarolím, T. Jůza, M. Kratochvíl, J. Peterka \& M. Tušer. 2009. Long-term development of fish populations in the Rímov Reservoir. Fish. Manag. Ecol., 16: 121-129.

Scharf, W.R., L. Heermann, , U. König \& J. Borcherding. 2009. Development of abundance and size structure of young-of-the-year perch populations using three methods. Fish. Res., 96: 77-87.

Sed’a, J. \& I. Dostálková. 1996. Live sieving of freshwater zooplankton: a technique for monitoring community size structure. J. Plankton Res., 18: 513-520.

Received: February 2009

Accepted: May 2009
Sed'a, J.\& J. Kubečka. 1997. Long-term biomanipulation of Rimov Reservoir (Czech Republic). Hydrobiologia, 345: 95-108.

Sed'a, J. \& M. Devetter. 2000. Zooplankton community structure along a trophic gradient in a canyon-shaped dam reservoir. J. Plankton Res., 22: 1829-1840.

Sed’a, J., K. Kolářová, A. Petrusek \& J. Macháček. 2007. Daphnia galeata in the deep hypolimnion: spatial differentiation of a "typical epilimnetic" species. Hydrobiologia, 594: 47-57.

Tischler, G., H. Gassner \& J. Wanzenböck. 2000. Sampling characteristics of two methods for capturing age- 0 fish in pelagic lakes habitats. J. Fish Biol., 57: 1474-1487.

Van Densen, W.L.T. \& J. Vijverberg. 1982. The relations between $0+$ fish density, zooplankton size and the vulnerability of pikeperch, Stizostedion lucioperca, to angling in the Frisian lakes. Hydrobiologia, 95: 321-336.

Van Dijk, P.L.M., G. Staaks \& I. Hardewig. 2002. The effect of fasting and refeeding on temperature preference, activity and growth of roach, Rutilus rutilus. Oecologia, 130: 496-504.

Vašek, M., J. Kubečka \& J. Sed'a. 2003. Cyprinid predation on zooplankton along the longitudinal profile of a canyonshaped reservoir. Arch. Hydrobiol., 156: 535-550.

Vašek, M. \& J. Kubečka. 2004. In situ diel patterns of zooplankton consumption by subadult/adult roach Rutilus rutilus, bream Abramis brama, and bleak Alburnus alburnus. Folia Zool., 53: 203-214.

Vašek, M., J. Kubečka, J. Peterka, M. Čech, V. Draštík., M. Hladík, M. Prchalová \& J. Frouzová. 2004. Longitudinal and vertical spatial gradients in the distribution of fish within a canyon-shaped reservoir. Int. Rev. Hydrobiol., 89: 352-362.

Vašek, M., J. Kubečka, J. Matěna. \& J. Sed’a. 2006. Distribution and diet of $0+$ fish within a canyon-shaped European reservoir in late summer. Int. Rev. Hydrobiol., 91: 178194.

Vijverberg, J., M. Boersma, W.L.T. Van Densen, W. Hoogenboezem, E.H.R.R. Lammens \& W.M. Mooij. 1990. Seasonal variation in the interactions between piscivorous fish, planctivorous fish and zooplankton in a shallow eutrophic lake. Hydrobiologia, 207: 279-286.

Wanzenböck, J., J. Matěna \& J. Kubečka. 1997. Comparison of two methods to quantify pelagic early life stages of fish. Arch. Hydrobiol. Spec. Iss. Adv. Limnol., 49: 117-124. 